\title{
A LEITURA COMO FAZER CRÍTICO: O POTENCIAL EMANCIPATÓRIO DOS CLÁSSICOS À PARTIR DE MARCUSE
}

\author{
FERREIRA, Pamella Thais Magalhães ${ }^{1}$ \\ MARANHÃ̃, Carolina Machado Saraiva de Albuquerque ${ }^{2}$
}

\begin{abstract}
RESUMO: O trabalho teve como objetivo contribuir para com o debate crítico no que se refere à importância da leitura dos clássicos na administração, uma vez que seu processo instrutivo direciona-o para uma atuação acrítica, funcional que os reduzem a cuidadores de capital como maneira de perpetuar o sistema econômico vigente, enquanto os clássicos poderão propiciar a desnaturalização da realidade, bem como proporcionar nos administradores o uso da razão subjetiva de forma potencial em detrimento das técnicas replicantes de conhecimento. Para o alcance de tais objetivos, apresenta-se a obra: A ideologia da Sociedade Industrial: O Homem Unidimensional (1973) de Herbert Marcuse como um clássico capaz de representar uma alternativa que possibilite a afluência de reflexões críticas nos sujeitos, especialmente nos graduandos em administração. Diante das denúncias da obra marcuseana em conjunto com fatores que levam ao entendimento da importância dos clássicos, acredita-se na leitura da obra de Herbert Marcuse (1973) como uma leitura, um resgate necessário, uma vez que sua obra se comporta como uma alternativa enquanto possibilidade de proporcionar a desnaturalização do universo concreto, através de mediações históricas, desencadeando na afluência crítica e implicando no despontamento de administradores reflexivos, autônomos, capazes de negar o universo de coisas estabelecidas, de promover a transformação qualitativa e principalmente na sua constituição de sujeito ético que transformará o meio mais justo e igualitário para todos.
\end{abstract}

Palavras-chave: Clássicos. Marcuse. Administração. Crítica.

SUMMARY: This work ai ms to contribute towards critical debate regarding the importance of reading the classics in the administration, since its instructional process directs you to an uncritical performance, functional to reduce the capital caregivers as a way to perpetuating the current economic system, while the classic will provide the denaturalization of reality as well as providing the administrators the use of subjective reason potential form at the expense of replicating knowledge techniques. To achieve these objectives, it presents the work: Ideology of Industrial Society: The One-Dimensional Man (1973) Herbert Marcuse as a classic can be an alternative that enables the flow of critical reflections on the subject, especially in students in management. Faced with complaints of Marcuse work together with factors that lead to the understanding of the importance of the classics, it is believed the reading of the work of Herbert Marcuse (1973) as a reading, a necessary rescue, since his work behaves as an alternative as a possibility to provide the denaturalization of the concrete universe, through historical mediations, triggering the critical supply and implying the appearance reflective, autonomous managers, able to deny the universe of things established, to promote qualitative transformation and especially in its constitution of subject ethical that will transform the fairest and equal for all.

Keywords: Classics. Marcuse. Administration. Criticism.

RESUMEN: Este trabajo tiene como objetivo contribuir al debate crítico sobre la importancia de la lectura de los clásicos de la administración, ya que su proceso de instrucción le dirige a una actuación poco crítica y funcional para reducir los cuidadores de capital como una forma de perpetuando el sistema económico actual, mientras que el clásico proporcionará la desnaturalización de la realidad, así como proporcionar a los administradores el uso de la razón subjetiva forma potencial a expensas de replicar las técnicas de conocimiento. Para lograr estos objetivos, se presenta la obra: La ideología de la sociedad industrial: El hombre unidimensional (1973) Herbert Marcuse como un clásico puede ser una alternativa que permite el flujo de reflexiones críticas sobre el tema, sobre todo en los estudiantes de la administración. Ante las quejas de Marcuse trabajar junto con los factores que conducen a la comprensión de la importancia de los clásicos, se cree que la lectura de la obra de Herbert Marcuse (1973) como una lectura, um rescate es necesario, ya que su obra se comporta como uma alternativa como una posibilidad para proporcionar la desnaturalización del universo concreto, a través de mediaciones históricas, lo que provoco el

\footnotetext{
${ }^{1}$ Graduação UFOP

${ }^{2}$ Professora Adjunta UFOP
} 
suministro crítico y que implica los despontamento reflectantes, gestores autónomos, capaces de negar el universo de las cosas establecidas, para promover la transformación cualitativa y sobre todo en su constitución del sujeto ética que va a transformar la más justa e igual para todos.

Palabras Clave: Clásicos. Marcuse. Administración. La crítica.

\section{INTRODUÇÃO}

\section{O PROCESSO INSTRUTIVO DOS ADMINISTRADORES}

O processo de formação dos administradores lida atualmente com uma dicotomia em seu direcionamento no que se refere à sociedade e mercado econômico. Sua formação exige uma capacidade reflexiva e crítica do todo enquanto o mercado lhe exige um pensamento e comportamento orientados para a perpetuação e reprodução da atividade econômica. Diante disso, para Barcelos, Dellagnelo e Saliés (2011) a formação do administrador é fundamentada na reprodução do sistema econômico vigente, perdendo a capacidade holística e reflexiva, se organizando para o alcance de objetivos, limitando-se como ser humano por ser concebido como fator operacional.

De acordo com os pensamentos de Aktouf (2014) a formação do administrador centrada na ótica do alcance de objetivos empresariais torna passível a sua natureza centrada na lógica da reprodução, uma vez que as escolas de gestão são ambientes elitistas e até mesmo conservadores, que buscam formar administradores que irão reproduzir os mesmos modelos e maneiras de pensar dos dirigentes atuais. Aktouf (2014) desconsidera a administração como ciência e revela a sua faceta ideológica, doutrinária, uma vez que o caráter cientifico busca a compreensão de algo e, todavia, a administração se consolida de forma reducionista, cabendo apenas as funções e técnicas de "fazer dinheiro". Para o autor, para que a Administração seja considerada como fator de mudança, o processo formativo não deve ser catalisado sobre a reprodução de ideias e modelos administrativos, bem como na utilização de dirigentes como modelos a serem seguidos.

Aktouf (2014) também se refere ao problema do caráter matematizante da formação, que busca uma imitação ideal de um computador, se concentrando nas decisões rápidas e em um raciocínio formal:

Esse modo de raciocínio não favorece o desenvolvimento da inteligência, da sensibilidade, da intuição; favorece, antes, a aquisição de automatismos e de condicionamentos; é matemático, positivista e impessoal, se constrói para além da sensibilidade humana. Ele conduz à busca cega do lucro e da rentabilidade que são indiferentes ao sofrimento humano, ao desemprego, à miséria, à poluição e a outros problemas causados pela lógica economista e maximizadora dominantes. A matematização da economia que faz do cálculo e do livre mercado os pontos de referência mais marcantes da formação em administração dá uma visão errônea da realidade. Devemos desmistificar essa crença implícita que o mercado e o cálculo econômico são suficientes por si sós para acertar os problemas todos (AKTOUF, 2014, p. 153 - grifo nosso).

Nicolini (2003) ao falar sobre o processo de formação dos administradores relata a forma acrítica desse processo ao referir-se ao aprendizado analogamente a de uma cadeia produtiva, de forma que os alunos são recebidos como matéria prima, docilizados, educados e formatados pelo processo de entrada até a saída. Sobre o aprendizado o autor afirma que os alunos se comportam como recipientes dispostos a serem preenchidos pelos conteúdos ministrados pelos docentes. Quanto melhores recipientes forem, melhores educandos se tornam. 
Maranhão e Motta (2007) em um estudo realizado tendo análises de revistas da área de administração como instrumento é denunciado o caráter da "consciência ingênua" (FREIRE, 1989) dos administradores para com os veículos de informação, bem como também, para com os meios de acesso e a formação em que são submetidos. As autoras ressaltam que a formação dos administradores permite a alienação e não reflexão sobre o comprometimento do trabalho desempenhado com a "autovalorização do capital". (MARANHÃO, MOTA, 2007, p. 2).

Concomitantemente a isso, os administradores em sua formação tem sido alvo do consumo da literatura do pop-management. Essa literatura, conforme explicado por Wood JR. e de Paula (2002) são compostas por feitos grandiosos, metodologias para o progresso que perpetuam a ilusão de soluções fáceis para os malefícios a que as organizações estão expostas. Ainda segundo Wood JR. e de Paula (2002) o pop-management é instrumento de consumo de muitos executivos, consultores, alunos e até mesmo professores do ramo de gestão.

Sobre o pop-management Buss, et al. (2014) afirma que a mesma tem o papel de orientar o gestor através da disseminação das melhores práticas, a um sucesso profissional devido a um bom desempenho, o que irá reforçar a sua imagem promissora, capaz de prover transformação a social, por ter uma razão além do que é estabelecido (capacidade empreendedora). Por outro lado, pode ser considerada a perspectiva de que esse tipo de literatura através de uma linguagem divertida exerce poder "psicomanipulador", capaz de promover a exploração econômica do trabalhador juntamente com a adoção de uma vida social alienada, conforme defendido por Wood Jr. e de Paula (2002, apud TRAGTENBERG, 1980).

Contudo, Aktouf (2014) deixa evidente a sua confiança em uma transformação da profissão dos administradores através de mudanças de cunho pedagógico. Dentre essas mudanças, Aktouf (2014) cita o poder da leitura dos clássicos como uma forma de se fazer contato com uma cultura geral, que desencadeie pensamentos questionadores e reflexivos nos administradores em detrimento da absorção técnica sofrida pelo processo formativo.

A reabilitação dos grandes autores clássicos apela para uma maior cultura geral nos conteúdos de ensino de administração. [...]Infelizmente, as escolas de administração são geralmente alérgicas à cultura geral, porque ela implica em questionamentos, inquietudes, angústias, rediscussões que podem frear a ação, contrariamente aos cálculos e à inteligência artificial que são muito mais valorizados. $O$ questionamento das humanidades é, com efeito, um método que conta muito no trabalho pessoal dos estudantes, na sua implicação como pessoas e não somente como neurônios e capacidade de cálculo ou capacidade de desenvolver os reflexos, os automatismos. A implicação pessoal é angustiante; angústia e o questionamento sobre os fundamentos, sobre os valores, entram em contradição com a vontade de formar pessoas para a decisão rápida, para a ação. (AKTOUF, 2014, p. 153-154).

Analogamente, Barcelos, Dellagnelo e Saliés (2011), exaltam a responsabilidade da universidade na construção de indivíduos críticos, emancipados e atuantes na sociedade, afirmando que seu papel se estende para além do cumprimento de uma capacitação para o mercado de trabalho e que, em especial à administração, deve-se dar suporte para que uma compreensão que transcenda perspectiva instrumental, funcionalista, que os definem como meros cuidadores de capital seja alcançada. É importante que os administradores se formem sabendo de sua capacidade de construção social e entenda as possibilidades que o cercam. Os autores ressaltam ainda que enfoque curricular dos cursos de Administração são fontes ideológicas, reprodutoras da lógica dominante, que enfatizam uma racionalidade instrumental, utilitarista, repelindo as alternativas de transformação. Para tal, Barcelos, Dellagnelo e Saliés (2011) sustentam a ideia de que as possibilidades que se baseiem em alternativas de alcance das necessidades sociais em diferentes 
espaços e momentos históricos devem emergir e serem enunciadas.

Tendo isso posto, estudos como o de Maranhão e Motta (2007) contribuem significativamente com uma possibilidade de alternativa. As autoras evidenciam a importância de leituras críticas para a formação dos administradores, bem como o papel de veículo dos docentes nessa realização. As autoras não se referem a uma leitura mecanizada, mas sim, uma leitura crítica, capaz de desvelar conteúdos encobertos pelo poder dominante, uma leitura política que permita com que os mesmos se despertem da imagem cândida que se tem sobre as coisas do mundo, desvelando as representações calafetadas nas palavras. As autoras defendem ainda que as leituras críticas, dialéticas, a partir de sua construção histórica garantem um processo de problematização em que sujeitos possam se portar como agentes que constituem a própria realidade. A capacidade de realização das leituras críticas evita uma postura de alienação favorecendo o esforço reflexivo e interpretativo pelos alunos, permitindo-os a mediação sobre a sua própria atuação enquanto sujeito e profissional (MARANHÃO,MOTTA, 2007).

Através do confronto entre as realidades presentes nas mídias burguesas e nas das "minorias", os discentes poderão iniciar o processo de aprendizagem crítica, percebendo que a realidade social é muito mais diversa que aquela presente nos manuais e que uma decisão administrativa qualquer deve considerar a totalidade envolvida (MARANHÃO, MOTA, 2007, p. 12).

Concomitantemente a isso Meneguetti, Filho e Azevêdo (2014a) defendem a importância da leitura de obras clássicas na administração. Ao afirmarem particularmente sobre as pesquisas em administração é reforçada a ideia de que a leitura dos clássicos impacta em uma não estagnação e isolamento intelectual, pois, a leitura de um clássico diz sobre a sua identidade enquanto sujeito social, ou seja, traz implicações epistemológicas. Os autores esclarecem ainda que, o afastamento dos clássicos leva por um lado a uma maior aproximação com técnicas metodológicas, porém, na mesma medida "a substituição de suas narrativas clássicas por conhecimentos parcializados e restritos a resultados de pesquisas parecem ter relação com uma crise na formação autônoma na administração.” (MENEGUETTI, FILHO; AZEVÊDO, 2014 p. 706). Para eles esse beneficiamento de técnicas e métodos de pesquisa, em perda dos alicerces epistemológicos e políticos que os sustentam, leva a um enfraquecimento do desenvolvimento intelectual em longo prazo. Os autores sustentam ainda que os clássicos tem conteúdos enriquecedores, capazes de instigar reflexões profundas até mesmo sobre os próprios paradigmas ocultos na construção de conhecimento na administração.

[...] os clássicos atuam como vias de interdisciplinaridade para a constituição de provocações e reflexões que levam a autonomia da área para além da incorporação de aspectos meramente metodológicos, quase sempre vinculados às ciências tradicionais. (MENEGUETTI, FILHO; AZEVÊDO, 2014 p. 707).

Diante disso, acredita-se na leitura dos clássicos, como mais uma alternativa ao pensamento crítico e como indisposição à "consciência ingênua" (FREIRE, 1989), pois, os mesmos tem a capacidade de desencadear pensamentos reflexivos e questionadores na administração, em detrimento do pensamento norteado pelos interesses particulares, baseados em metodologias, práticas e modelos administrativos tomados de características funcionais, acríticas e positivas, fazendo com que os administradores se tornem sujeitos de seu processo de aprendizado, refletindo epistemologicamente sobre suas decisões.

Destarte, a partir da concepção sobre a importância da leitura dos clássicos como peça chave na constituição da identidade dos sujeitos, o presente artigo procura promover uma reflexão acerca da importância da leitura da obra de Herbert Marcuse: A Ideologia da Sociedade Industrial - O Homem 
Unidimensional (1973), como forma de influenciar a construção de sujeitos críticos, com pensamento antagônico e dialético, capaz de desnaturalizar os fatos dados como pertencentes à realidade, promovendo o projeto da teoria crítica de que "a vida humana vale a pena ser vivida, ou melhor, pode ser ou deve ser tornada digna de se viver" (MARCUSE, 1973, p. 14). A obra de Marcuse denuncia os desdobramentos da industrialização e tecnologia como pilares do caráter totalitário em que forças opressoras da sociedade capitalista atual se mantêm e, coloca ainda a administração como um dos responsáveis por essa dominação e totalitarismo. A partir da leitura dessa obra acredita-se que os administradores possam ser libertados de suas práticas reducionistas, que os limitam a meros cuidadores dos interesses particulares, dando lugar a administradores autônomos, capazes de se portarem como indivíduos, seres transformadores e responsáveis pela possibilidade de uma mudança qualitativa.

\section{O HOMEM UNIDIMENSIONAL: UM PERCURSO FORMATIVO}

"A Ideologia da Sociedade Industrial - O Homem Unidimensional" (1973) é uma obra do filósofo frankfurtiano Herbert Marcuse. Esse filósofo destaca-se por em toda a sua carreira preocupar-se em construir uma filosofia que se unisse a política, que se voltasse para a emancipação e para o aprimoramento da condição da vida humana (LOUREIRO, 2005). "Em resumo, Marcuse procura renovar o marxismo, e alarga o campo de suas preocupações ao teorizar sobre a dimensão subjetiva da vida humana vinculada à mudança social." (LOUREIRO, 2005, p. 10).

As definições da Sociedade e do Homem Unidimensional tem revelado grande importância na atualidade, prova disso, é a utilização dos seus estudos em trabalhos de teoria crítica mesmo após mais de 50 anos da publicação desta obra. Além disso, suas características são assaz aplicáveis às instituições e à sociedade capitalista globalizada atual. (BASTOS, 2014). Kellner (2011) deixa claro o seu desprezo pela característica dada a esse retorno como nostálgico e frisa a contribuição da obra para o momento histórico contemporâneo. Ele ainda classifica esse retorno como caráter emergencial, pois, embora seja uma obra dos anos 1960, não se refere às particularidades passadas, dá-se justamente ao contrário, a obra de Marcuse (1973) indica tendências (KELLNER, 2011).

Diante de sua perspectiva crítica como forma de construir a realidade sobre o mundo, a obra de Herbert Marcuse (1973) denuncia o aparato produtivo da era industrial, a tecnologia, bem como a consequente divisão do trabalho como responsáveis pela redução do pensamento crítico dos sujeitos e sua capacidade de negação a ordem estabelecida, consolidando assim, a sociedade unidimensional (sem poder de negação, uma sociedade acrítica) e também o homem unidimensional que ao ser mimetizado na referida sociedade e invadido em sua consciência e individualidade, se comporta como tal. A sociedade industrial, unidimensional, assentou sua dominação baseada na técnica e ciência, com aparelhos de produção, distribuição de tecnologia e práticas administrativas que se baseiam em interesses particulares (RASTOVIC, 2013). A tecnologia é libertada a partir dos controles de autoridades e tornou-se fator de dominação em si (RASTOVIC, 2013).

A sociedade unidimensional ao ser firmada no progresso técnico, na industrialização e na expropriação do homem de seu próprio processo de trabalho como consequência do avanço do sistema capitalista, transformou-se em uma sociedade de dominação e totalitarismo, administrando o seu controle nas esferas política, econômica e social ao mesmo tempo em que transforma disfarçadamente os interesses particulares em interesses sociais.

Entretanto, a dominação é encoberta pelo véu do progresso técnico, do padrão de vida crescente, 
do atingimento das necessidades materiais e até mesmo psíquicas dos sujeitos. A sociedade unidimensional em sua administração dispõe aos indivíduos o alcance de necessidades materiais falsas (as que vão além do nível biológico) que ao proporcionar no indivíduo uma consciência feliz (também falsa), ou uma "euforia na infelicidade" conforme adjetivado por Marcuse (1973, p. 26), faz com que o mesmo seja condescendente com o sistema de coisas estabelecido e se submeta cada vez mais às exigências dessa sociedade como forma de atingimento das satisfações de suas necessidades. De acordo com Whitfield (2014) a referida obra marcuseana permite perceber como a ideologia dessa sociedade oculta à dominação e a alienação e, que o protesto a essa condição deve começar primeiramente com o reconhecimento espiritual das formas precárias de vida. Marcuse (1973) demonstra que a repressão sofrida é internalizada nos sujeitos de forma punitiva, de forma que o pensamento negativo dos sujeitos sofre uma auto-restrição que acabam por servir como uma limitação à energia necessária para a mudança qualitativa (WOLFF, 2011).

Graças ao progresso técnico a sociedade torna-se cada vez mais capaz de suprir as necessidades supérfluas do indivíduo ao mesmo tempo em que perpetua essas mesmas necessidades (até mesmo através da obsolescência planejada), fazendo com que os mesmos se abstenham, também progressivamente, de sua individualidade e sejam suprimidos a um trabalho repressivo que violenta em troca do atingimento dessas mesmas necessidades, estando assim, os indivíduos certos de desfrutar de sua liberdade, autonomia e da felicidade de um padrão de vida crescente. Ora, se essa dominação reproduz o sentimento e a consciência feliz, não há motivos aparentes para que tal realidade seja desconstruída. A sociedade reforça a sua condição acrítica e unidimensional quanto mais é capaz de atender as necessidades dos indivíduos pelas formas em que é organizada. O pensamento dialético e a razão subjetiva são aniquilados. Logo, a dominação revela sua faceta evolutiva em condicionamento e em racionalidade instrumental (MARCUSE, 1973).

As formas espoliadas a que o indivíduo se submete, as catástrofes, a destruição, a riqueza sem precedente, o trabalho estupefaciente, a demanda programada, a produção maximizada contribuem para um tipo de barbárie, essa é aceitável e até mesmo lógica. As necessidades materiais, os ideais progressistas e o elevado padrão de vida promovem o conforto, a consciência feliz, fazendo com que o indivíduo aja em defesa desse status quo. (MARCUSE, 1973).

A automatização dessa sociedade também exerce influência sobre a capacidade crítica dos indivíduos, os mesmos foram expropriados de sua autonomia no trabalho, levando a instalação até mesmo do ritmo de seu trabalho pelas máquinas. A força e pensamento humanos foram projetados e otimizados na maquinaria. Contudo, essa automatização como forma de concentração da força produtiva do homem, ao invés de proporcioná-lo a liberdade, o tempo livre, o escravizou e estendeu o seu tempo de trabalho. $\mathrm{O}$ surgimento do progresso técnico com o ideal de aprimorar a vida humana se transforma em ideologia. (MARCUSE, 1973).

Os indivíduos da sociedade unidimensional, os homens unidimensionais, não conseguem traspor o pensamento dialético, se tornam seres que mimetizaram na sociedade, absorvendo sua ideologia a partir da identificação da realidade pelo universo concreto. Os discursos passaram a ter conotação de propaganda, os conceitos perderam seus sentidos verdadeiros, a linguagem da sociedade industrial, unidimensional é uma linguagem constantemente política e comercial. "A locução é privada das mediações que são as etapas do processo de cognição e avaliação cognitiva." (MARCUSE, 1973, p. 93).

Marcuse (1973) apresenta ainda a sociedade unidimensional como uma sociedade de dominação, totalitária e, apresenta a administração como um de seus pilares. Marcuse (1973) se refere a essa sociedade como uma sociedade administrada por a mesma ser levada a condescender com suas formas de vida estabelecidas menos conspicuamente que por coerção ou violência eminente. Para ele, os proprietários do 
capital perderam sua identidade como responsáveis pelo caráter totalitário e da dominação social, essa responsabilidade foi transmitida à gerência. $\mathrm{O}$ funcionalismo, utilitarismo, bem como, a racionalidade instrumental e o positivismo invadiram todas as formas de organização e administração. "A dominação se transfigura em Administração" (MARCUSE, 1973, p. 49). Marcuse (1973) relata também que o fato dos cargos gerenciais compartilharem suas mentes nas formas de trabalho não os transforma em seres autônomos e menos escravizados, o autor deixa claro que a condição de escravo não se dá pela força física no trabalho, mas sim, na condição de coisa e de instrumento para cumprimento da ideologia industrial. Marcuse vai mais além e destaca até mesmo as características positivistas das pesquisas administrativas como forma de sustentação e confirmação à ideologia dominante, por transpor particularidades de pesquisas a um universo generalista, com traduções baseadas somente no universo concreto e hegemônico da sociedade. Conforme colocado por Feenberg (2013), Marcuse (1973), desenvolve a ideia de que a racionalidade tecnológica científica está a serviço de práticas capitalistas, que a estrutura racional moderna, está ligada ao cumprimento de exigências do controle produtivo industrial. Para Marcuse (1973), essas pesquisas são o pensamento "metodicamente colocado a serviço da exploração e do aprimoramento das condições sociais existentes, dentro da estrutura das instituições sociais existentes." (MARCUSE, 1973, p. 110).

Esta é uma forma pura de servidão: existir como instrumento, como uma coisa. E esta forma de existência não é ab-rogada se a coisa é animada e escolhe o seu alimento material e intelectual, se não se apercebe de que é uma coisa, se é uma coisa bonita, limpa e móvel. Inversamente ao tender a espoliação para tornar-se totalitária em virtude de sua forma tecnológica, os próprios organizadores e administradores se tornam cada vez mais dependentes da maquinaria que eles organizam e administram. E essa dependência mútua não é mais relação entre senhor e servo, já rompida na luta pelo reconhecimento mútuo, mas, antes um círculo vicioso que inclui tanto o senhor como o servo. Os técnicos de fato dominam, ou será o seu domínio daqueles que confiam nos técnicos como seus planejadores e executores (MARCUSE, 1973, p. 49-50).

Destarte, diante dos conteúdos desvelados por Marcuse (1973), acredita-se que a obra apresenta contribuições assaz importantes para o campo formativo dos administradores, uma vez que a mesma delata os sentidos ideológicos da profissão, bem como a sua objetividade funcional, acrítica, reducionista, coisificada, como agente responsável por transmitir aos indivíduos a ideologia unidimensional, apresentando contraste com sua função transformadora do meio, capaz de tomar decisões totais através de sua autonomia. Além disso, como defendido por Cunningham (2013), Herbert Marcuse acreditava na transformação para um futuro melhor como um poder possível graças a ações estudantis. Os estudantes universitários representavam a população mais adequada para Marcuse para um programa filosófico e crítico e, ainda, para Marcuse (1973) a afluência da razão crítica é uma predestinação à libertação social que se dará contra a submissão à dominação e administração. (PARRY, 2013).

\section{A IMPORTÂNCIA DA LEITURA DOS CLÁSSICOS}

Para que a importância da leitura dos clássicos seja transparecida é igualmente importante a sua conceituação. Em pesquisas realizadas nota-se uma grande dificuldade da tradução do termo "clássico" em um conceito ou significado. Assim como as obras que recebem essa adjetivação, clássico, é uma palavra que transcende a concretude, é abstrato, por isso, existe a dificuldade de transformá-la em algo objetivo, com a estrutura de significados e conceitos. 
Meneguetti, Filho e Azevêdo, (2014b) afirmam que a tentativa de significação do termo "clássico" é um investimento positivista e funcionalista que desemboca numa instrumentalização do conceito, além de apresentar uma perspectiva reducionista do mesmo e, diante disso, em suas pesquisas tentam desnaturalizar esse caráter utilitarista desprezando sua conceituação como algo simplório ou que o reduza à sua utilização ou aplicação. Para eles o paradigma envolto dos clássicos está ligado a sua concepção utilitarista e, "um paradigma não deve simplesmente ser compreendido como um limite a ser superado pela necessidade que está em permanente potência." (MENEGUETTI, FILHO;AZEVÊDO, 2014b, p.738).

Os autores vão mais além ao não defenderem a conceituação de clássico, pois, para eles um conceito ao ser instituído é produto de um desejo por certezas e verdades de forma rígida. A escolha pela não conceituação não significa para os autores uma abstenção do processo de conceituar e sim, se refere a uma "não dogmatização", pois, dogmatizar o conceito é ir contra o princípio científico. "A não dogmatização do conceito de clássico permite pensar o próprio clássico a partir do não clássico, das possibilidades do vir a ser" (MENEGUETTI, FILHO;AZEVÊDO, 2014b, p.743). O clássico é algo que caso conceituado apresentará uma definição transitória, como resultado de uma concepção sócio-historica. O clássico é algo que transcende a materialização dos elementos que constituem o conhecimento. (MENEGUETTI, FILHO;AZEVÊDO, 2014b).

Assim, utiliza-se para fins de orientação no que se refere ao entendimento da essência dos clássicos, o trabalho de Calvino (1993). O autor contribui com a definição de características que permitem a reflexão sobre o que é um clássico e o que não é, provocando assim, o reconhecimento do que os clássicos podem vir a ser. Dentre as várias características exaltadas por ele, uma delas defende que os clássicos são livros atemporais, que nunca se esgotam na leitura, "são aqueles livros dos quais, em geral, se ouve dizer: 'estou relendo... ' e nunca 'estou lendo... "' (CALVINO, 1993, p. 9). Além disso, ele relata também que os clássicos ao serem relidos desvendam detalhes que anteriormente não tinham sido observados, isso se dá tanto pela mudança histórica quanto pela maturidade alcançada pelo leitor ao longo do tempo, afirmando que: "toda leitura de um clássico é uma leitura de descoberta como a primeira" e ainda que: "um clássico é um livro que nunca terminou de dizer aquilo que tinha pra dizer" (CALVINO, 1993, p. 11). Calvino também relata que na releitura podemos relembrar as coisas que fazem parte de nossos "mecanismos interiores" que haviam sido esquecidos. Os clássicos exercem sobre nós uma influência particular que permite a mimese da consciência individual.

Calvino (1993) ressalta a importância da leitura dos textos clássicos originais em detrimento das críticas, comentários e interpretações, pois, as mesmas são utilizadas como "cortinas de fumaça" para ocultar o que o texto tem a dizer e que só pode ser compreendido sem intermediários, até porque "nenhum livro que fala de outro livro diz mais sobre o livro em questão". Sendo assim: "um clássico é uma obra que provoca incessantemente uma nuvem de discursos críticos sobre si, mas continuamente as repele para longe" (CALVINO, 1993, p. 12). Para ele os clássicos não necessariamente nos colocam diante de algo novo ou inesperado, eles também nos fazem perceber algo que sempre soubemos ou acreditávamos saber, mas em sua leitura percebemos que antes ele havia denunciado ou de forma particular ao clássico essa descoberta era ligada: "os clássicos são livros que, quanto mais pensamos conhecer por ouvir dizer, quando são lidos de fato mais se revelam novos, inesperados, inéditos" (CALVINO, 1993, p. 12). Dessa forma, a atualidade do clássico pode permanecer ainda que esse seja, de fato, "velho". (TEIXEIRA, ZANOTELI, CARRIERI, 2014, p. 156).

Ademais, Calvino (1993) destaca a distinção ou até mesmo a contradição (como enfatizado por muitos estudiosos) entre os clássicos e a atualidade. Para ele, a leitura dos clássicos não deve ser "contaminada" pelas atualidades, porém, ao mesmo tempo, Calvino (1993) defende primeiramente que para a leitura dos clássicos deve ser estabelecido "de onde eles estão sendo lidos" (CALVINO, 1993, p. 
14), entendendo a relação do mesmo com o passado, presente e futuro, pois, do contrário poderá ocorrer à perda do leitor e da obra numa nuvem atemporal. Para isso, o autor define que nas leituras dos clássicos, a atualidade deve se comportar como um "rumor do lado de fora da janela", de forma que a alternância entre os clássicos e as atualidades seja sabiamente dosada. Dessa forma, o autor define: "clássico é aquilo que tende a relegar as atualidades à posição de barulho de fundo, mas ao mesmo tempo não pode prescindir desse barulho de fundo." (CALVINO, 1993, p. 15). Calvino vai mais além e destaca a capacidade de denúncia que o clássico tem diante da atualidade e o define também como: "aquilo que persiste como rumor mesmo onde predomina a atualidade mais incompatível.”.

É possível que os clássicos, tal como chamamos na linguagem corrente, sejam justamente isso: aquelas obras nas quais, de modo sempre enigmático, o tempo se oferece a nós para uma apropriação singular e criativa. São as obras cuja verdade nunca se fecha em si mesma, mas permanece aberta e, por isso, acontecendo - e nos tocando. No contato com os clássicos, experimentamos, então, o acontecimento de sua verdade que, por ser não apenas fruto do tempo, mas também agente do tempo, jamais cessa de acontecer: ontem, hoje e amanhã. (DUARTE, 2008, p. 195).

No que tange à importância da leitura dos clássicos Teixeira, Zanoteli e Carrieri (2014) ressaltam que essa leitura se torna importante por participar do processo de socialização secundária dos pesquisadores e, consequentemente em sua constituição como tal. O processo de socialização secundária é "qualquer processo posterior que introduza um indivíduo já socializado em novos setores do mundo objetivo de sua sociedade.” (TEIXEIRA, ZANOTELI;CARRIERI, 2014, p 157), é o processo de formação dos sujeitos pelas influências secundárias sofridas ao longo da vida dos indivíduos. Para os autores a leitura dos clássicos é parte constituinte desse processo, ou seja, a leitura dos clássicos irá desencadear num processo de socialização que irá construir os sujeitos, essa socialização internaliza-se no inconsciente, gerando concepções ontológicas e epistemológicas. No que se refere às influências de socialização secundária, em especial o papel da escola, Calvino (1993, p. 13) diz:

[...] Os clássicos não são lidos por dever ou por respeito mas só por amor. Exceto na escola: a escola deve fazer com que você conheça bem ou mal um certo número de clássicos dentre os quais (ou em relação aos quais) você poderá depois reconhecer os "seus" clássicos. A escola é obrigada a dar-lhe instrumentos para efetuar uma opção: mas as escolhas que contam são aquelas que ocorrem fora e depois de cada escola.

Além disso, Teixeira, Zanoteli e Carrieri (2014) relatam também a leitura dos clássicos como forma de constituição da identidade (enquanto processo infinito, uma metamorfose) dos sujeitos. Os autores expressam que a leitura dos clássicos provoca no leitor uma identificação individual e grupal, determinando sua identidade a partir e sua visão de si, de sua visão para com os outros e ao mesmo tempo dos outros para com ele. Essa constatação é a responsável por fazer com que os mesmos surjam como sujeitos donos do próprio processo de razão. Eles ressaltam também que não só os clássicos em que o sujeito aprova e consente fazem parte da constituição de sua identidade, os clássicos em que os mesmos se opõem fazem parte da construção dialética de si mesmo. A formação dos sujeitos como pesquisadores também é influenciada pelas posições políticas tomadas pelas referencias do pesquisador, para isso, Teixeira, Zanoteli e Carrieri (2014) defendem que a leitura dos clássicos não deve ser realizada de forma ingênua, ou ainda primordialmente, não deve ser feita a leitura ingênua dos leitores dos clássicos. 
Aqui cabe um alerta aos "replicantes", são àqueles que sem um olhar crítico tanto em relação aos textos originais quanto em relação à bibliografia posterior, passivamente "levam adiante" conteúdos vazios, movidos quase sempre por modismos. (TEIXEIRA, ZANOTELI, CARRIERI, 2014, p. 156).

Teixeira, Zanoteli e Carrieri (2014), concluem que a leitura dos clássicos, bem como a sua escolha, é importante para a consolidação dos sujeitos, para que seja possível compreender onde estamos e quem nós somos. Para tal, é importante que se tenha um contato direto com a obra e não com os trabalhos de seus interpretes, para que o processo de constituição dos sujeitos e o constituir científico não se comportem como réplicas, "colonialismo epistêmico". O entendimento dos clássicos através das melhores ferramentas permite não somente o conhecimento individual de cada pesquisador, mas também a compreensão da responsabilidade científica envolta da constituição e processo de pesquisa.

Portanto, acredita-se na importância da leitura dos clássicos por esse vir a ser capaz de catalisar a emancipação dos sujeitos, bem como o seu pensamento crítico e autônomo. Ao mesmo tempo não se trata a importância de sua leitura como uma seção conclusiva, pois, não há a intenção de apresentar certezas ou verdades reduzindo a sua importância a um caráter utilitarista e funcional, da mesma forma em que se prioriza a sua não conceituação como forma de abster-se de sua face ideológica. Como forma de elucidar tal concepção, adota-se a ideia de Calvino (1993, p. 16)

[...] A única razão que se pode apresentar é que ler os clássicos é melhor que não ler os clássicos. E se alguém objetar que não vale a pena tanto esforço, citarei Cioran (não um clássico, pelo menos por enquanto, mas um pensador contemporâneo que só agora começa a ser traduzido na Itália): "Enquanto era preparada a cicuta, Sócrates estava aprendendo uma ária com a flauta. 'Para que lhe servirá?' perguntaram-lhe. 'Para aprender esta ária antes de morrer'.

\section{OS CLÁSSICOS NA PERSPECTIVA MARCUSEANA}

“[...] Insistem os neoconservadores em que deve ser reconhecido o fato de os clássicos terem saído do mausoléu (...). É verdade, mas voltando à vida como clássicos, eles voltam à vida diferentes de si mesmos; são privados de sua força antagônica, do alheamento que foi a própria dimensão de sua verdade. O intento e a função dessas obras foram, assim, fundamentalmente modificados. (MARCUSE, 1973, p. 76).

Marcuse (1973) apresenta a problemática do Clássico, como ainda não havia sido exposto por outros pensadores. Este teria uma dupla função na sociedade, sendo uma reacionária e outra revolucionária. Compreender esta dupla função atribuída a um clássico é o início de uma compreensão crítica da realidade.

O clássico teria uma função reacionária quando apropriado pela ideologia vigente, que o transforma em fetiche, em peça de museu, em uma obra que fala de tempos passados, cuja vivacidade já não mais impacta na ação cotidiana presente. Chamada de concepção pessimista, Marcuse (1973) afirma que os mesmos ao invés de provocarem o caráter questionador diante da realidade, passam, assim, a comportarem-se de forma ideológica, positiva, reforçando o sistema de coisas estabelecido. Esta concepção de clássicos reduz a sua natureza abstrata, sua capacidade transcendente de provocar o pensamento autônomo, valendo-se apenas de uma face da significação dos clássicos, adotando a sua natureza funcional. A concepção reacionária dos clássicos é reducionista e operacional. 
Esta função do clássico encontra terreno fértil na sociedade capitalista, por ela hiperventilar a racionalidade instrumental e tecnocrática. Tal pode ser destacado na afirmação dos termos em seus conceitos operacionais e/ou em sua função ou utilidade. Para Marcuse (1973) a tradução do significado das palavras em conceitos dão a elas características funcionais, o significado irá referir-se a formas específicas das coisas funcionarem, a significados reducionistas, incapazes de abranger a significância universal, transcendente, abstrata da palavra. Marcuse (1973) acredita que essa tentativa de tradução deturpa os conceitos e a verdade sobre a sua representação, pois, existem conceitos que são transcendentes, de natureza abstrata, não podendo alcançar a plenitude de sua definição nos termos concretos, operacionais ou funcionais. $\mathrm{O}$ autor acredita que esse tipo de linguagem, repele a realidade histórica e serve de veículo de subordinação e coordenação. Marcuse (1973) acredita que a constituição dos conceitos se dá sobre a reflexão dialética, ou seja, sobre o movimento cognitivo sobre o que a coisa é e o que ela não é, ele acredita que os significados estão para além do contexto em que está sendo empregado. E, quando o desenvolvimento linguístico bloqueia o desenvolvimento conceitual, ele barra também a abstração e a mediação, "se se rende aos fatos imediatos, repele o conhecimento dos fatores que estão por trás dos fatos e, assim, repele o reconhecimento dos fatos bem como o conteúdo histórico destes." (MARCUSE, 1973, p. 102).

Ao dizer: "o relâmpago estronda", a criatura "não pensa meramente no estrondo do relâmpago, mas no próprio relâmpago que estronda", num sujeito que "passou a ação". E se uma sentença dá uma definição de seu sujeito, não dissolve o sujeito em seus estados ou funções, mas o define como estando nesse estado ou exercendo esta função. Sem desaparecer em seus predicados e sem existir como uma entidade antes e fora de seus predicados, o sujeito se constitui em seus predicados - o resultado de um processo de mediação que está expressado na sentença (MARCUSE, 1973, p. 102).

Marcuse (1973) acredita que a constituição dos conceitos se dá sobre a reflexão dialética, ou seja, sobre o movimento cognitivo sobre o que a coisa é e o que ela não é, ele acredita que os significados estão para além do contexto em que está sendo empregado. E, quando o desenvolvimento linguístico bloqueia o desenvolvimento conceitual, ele barra também a abstração e a mediação, "se se rende aos fatos imediatos, repele o conhecimento dos fatores que estão por trás dos fatos e, assim, repele o reconhecimento dos fatos bem como o conteúdo histórico destes.” (MARCUSE, 1973, p. 102).

O autor também adjetiva a linguagem funcional como anti-histórica, não admitindo o uso das palavras de forma que correspondam a perspectivas históricas de um passado como se ele fosse ultrapassado, sendo o seu significado importado exatamente no contexto presente sem tais mediações. Sendo assim, a liberdade pode significar escravidão, progresso pode significar regresso e democracia, coerção. Para Marcuse (1973) o reconhecimento das relações do passado com o presente milita contra a funcionalização do pensamento sobre a realidade estabelecida. $O$ pensamento se abre contra o fechamento da locução e do comportamento, "possibilita o desenvolvimento dos conceitos que desestabilizam e transcendem o universo fechado ao compreende-lo como universo histórico" (MARCUSE, 1973, p. 105). Além disso, o autor ainda assevera que o julgamento da consciência histórica torna-se pensamento crítico.

A lembrança do passado pode dar surgimento a perigosas introspecções e a sociedade estabelecida parece apreensiva com os conteúdos subversivos da memória. A lembrança é um modo de dissociação dos fatos dados, um modo de "mediação" que quebra, por alguns instantes, o poder onipresente dos fatos dados. A memória recorda o terror e a esperança passados. Ambos voltam a vida, mas enquanto, na realidade, aquele ressurge em formas sempre novas, esta permanece uma esperança. (MARCUSE, 1973, p. 104). 
A função revolucionária dos clássicos seria resgatada à medida em que se rompesse com a unidimensionalidade da sociedade industrial e tecnoburocrática. Marcuse (1973), defende-se que a leitura de sua obra enquanto clássico possibilita o pensamento dialético e afluência da racionalidade substantiva, em detrimento da razão instrumental, por permitir a conscientização dos significados ao confrontá-los com suas perspectivas históricas. O próprio autor acredita na possibilidade transformadora do resgate dessa consciência, a consciência histórica. Tendo isso posto, acredita-se que a característica atemporal dos clássicos, bem como seu caráter revelador ao ser relido, coadunam com uma alternativa que promova a transformação qualitativa da sociedade e dos meios de vida.

\section{A IDEOLOGIA DA SOCIEDADE INDUSTRIAL: UMA LEITURA NECESSÁRIA}

A conceituação do clássico é uma tentativa não só de funcionalizar ou instrumentalizar o conceito, mas também de deturpar sua natureza transcendente e abstrata, de forma consciente ou não, impondo barreiras à mediação histórica entre o passado e o presente, como forma de aplanar de forma espoliada a força de mais uma alternativa que possibilite o resgate da autonomia e crítica dos sujeitos, reforçando o caráter da dominação.

Contudo, este trabalho não buscou debruçar-se sobre a significação dos clássicos, mas sim, em denunciar o conteúdo da obra marcuseana que possibilita o confronto histórico e a capacidade de inspirar reflexões críticas, principalmente para o campo da Administração, pois, assim como defendido por Barcelos, Dellagnelo e Saliés (2011), deve haver um suporte para estudantes da área para que sua atuação venha a ser para além do cumprimento de tarefas instrumentais que os reduzem a cuidadores de capital e a um dos pilares da dominação, tal qual como é defendido por Marcuse (1973).

A partir da análise da obra de Marcuse (1973) em conjunto com as definições de Calvino (1993) é passível de constatação que a obra marcuseana se consolida como um clássico, pois, suas características e denúncias têm implicações bastante contemporâneas, até mesmo por promover a mediação histórica proporcionando reflexões críticas. Além disso, a obra de Marcuse (1973) por fazer construções dialéticas sobre o meio social e individual favorece a socialização e a constituição dos sujeitos.

Além disso, acredita-se no potencial desta referida obra de promover a transição de uma "consciência ingênua" (FREIRE, 1989) para a consciência crítica dos administradores, pois, a mesma servirá como uma perturbação diante das técnicas e instrumentos utilizados na administração, reforçando a estagnação e enfraquecimento intelectual em longo prazo que tem como resultado a crise na formação autônoma de administradores. Como de acordo com o que foi exposto no texto, principalmente no que se refere a socialização como forma de constituição dos sujeitos e a sua devida identificação, acredita-se na primordialidade de uma leitura crítica que proporcione o pensamento dialético, que denuncie o estado de coisas estabelecido e o condicionamento do indivíduo. Concomitantemente, denuncia-se a possibilidade de transformação a partir da leitura do clássico marcuseano para graduandos em administração, por essa ser uma obra que desencadeará na forma epistemológica de construção da realidade e não apenas sujeitos replicantes, sabendo que, sua substituição por leituras funcionais irão apenas reforçar o caráter totalitário denunciado nesta obra.

É importante ressaltar ainda, ideias de Maranhão e Motta (2007) da importância dos docentes como ativos no processo de inserção de leituras críticas nas universidades e, ao mesmo tempo a colocação de Calvino (1993) de que a escola tem o dever de apresentar aos seus alunos certo número de clássicos, de servir como instrumento, para que posteriormente o sujeito tenha condições de avaliar verdadeiramente a sua relação pessoal, de identificação com as obras que venha a escolher. Corroborando esse horizonte com 
as denúncias da obra marcuseana, acredita-se que o indivíduo que se identificar com tal obra, desencadeará uma mudança de consciência: "Os clássicos são os livros que exercem uma influência particular quando se impõem como inesquecíveis e também quando se ocultam nas dobras da memória, mimetizando-se como inconsciente coletivo e individual." (CALVINO, 1993, p. 10-11). E, "se o homem tiver aprendido a ver e a conhecer o que realmente é, agirá em concordância com a verdade. Epistemologia é, em si, ética e ética é epistemologia." (MARCUSE, 1973, p. 127).

Portanto, a leitura da referida obra poderá implicar no despontamento de administradores críticos, capazes de promover a transformação qualitativa e principalmente na sua constituição de sujeito ético que transformará o meio mais justo e igualitário para todos, pois, uma vez retirado o véu sobre a realidade dando fim à alienação, o sujeito não mais consegue agir contra essa verdade e realidade. Dessa forma, negar sua leitura como clássico, como possibilidade específica de melhor a condição da vida humana é ao mesmo tempo negar o projeto da própria teoria crítica, ou seja, negar "o julgamento de que vida humana vale a pena ser vivida, ou, melhor, pode ser ou deve ser tornada digna de se viver" (MARCUSE, 1973, p. 14).

\section{REFERÊNCIAS}

AKTOUF, O. Ensino de Administração: por uma Pedagogia para Mudança. Rev. Organizações \& Sociedade, América do Norte, 12, jun. 2014. Disponível em:

<http://www.portalseer.ufba.br/index.php/revistaoes/article/view/10810/7757> Acesso em: 02 Fev. 2016.

BARCELOS, R. M. C.; DELLAGNELO, E. H. L.; SALIÉS, G. P. Universidade, Sociedade e Formação do Administrador: Uma Reflexão Necessária. Administração: Ensino e Pesquisa. Rio de Janeiro. V. 12, n. 4, p.671-696. Out/Nov/Dez 2011.

BASTOS, R. L. Marcuse e o homem unidimensional: pensamento único atravessando o Estado e as instituições. R. Katál., Florianópolis, v. 17, n. 1, p. 111-119, jan./jun. 2014.

BUSS, R. N.; TAVARES A. M. M.; SANTOS, A. A.; O Pop-management e a Leitura como Diferencial na Formação do Gestor. XIV COLÓQUIO INTERNACIONAL DE GESTÃO UNIVERSITÁRIA - CIGU A Gestão do Conhecimento e os Novos Modelos de Universidade Florianópolis - Santa Catarina - Brasil 3, 4 e 5 de dezembro de 2014. Disponível em: $<$ https://repositorio.ufsc.br/bitstream/handle/123456789/131769/2014150.pdf?sequence=1\&isAllowed=y> Acesso em: 02 Fev. 2016.

CALVINO, I. Por que ler os clássicos. Tradução: Nilson Moulin. São Paulo: companhia das letras, 1993, (p. 9-16).

CUNNINGHAM, J. Praxis exiled: Herbert Marcuse and the one dimensional university. Journal of Philosophy of Education. v. 47, n. 4, p. 537-547, 2013.

DUARTE, P. O que faz de uma obra um clássico?. Revista Poiésis. Rio de Janeiro: Unisul, n. 11, p. 191213 , nov. de 2008 .

FEENBERG, A. Marcuse's Phenomenology: Reading Chapter Six of One-Dimensional Man. John Wiley \& Sons Ltd. Constellations Volume 20, Number 4, 2013, pp. 204 - 214.

FREIRE, P. Pedagogia do oprimido. Rio de Janeiro: Paz e Terra, 1968. 
KELLNER, D. M. On Marcuse: critique, liberation, and reschooling in the radical pedagogy of Herbert Marcuse. Estud. pesqui. psicol., Rio de Janeiro, v. 11, n. 1, abr. 2011, pp. 23-55. Disponível em: <http://www.e-publicacoes.uerj.br/index.php/revispsi/article/view/8752> Acesso em: 23 de novembro de 2015.

LOUREIRO, I. Herbert Marcuse - anticapitalismo e emancipação. Trans/Form/Ação, Marília, v. 28, n. 2, p. 7-20, 2005 .

MARANHÃO, C. M. S. A; MOTTA, F. M. V. “A Importância Do Ato De Ler”: Leituras Críticas na Formação do Administrador. In: Encontro da ANPAD, 31. 2007. Disponível em:

<http://www.anpad.org.br/admin/pdf/EPQ-A1752.pdf> Acesso em: 02. Fev. 2016.

MARCUSE, H. (1964) A Ideologia da Sociedade Industrial: O Homem Unidimensional. Trad. Giasone Peruá. Rio de Janeiro. 1973. (Edição Zahar Editores) 237p.

MENEGHETTI, F. K.; GUARIDO F. E. R.; AZEVEDO, A. Por que ler os clássicos no ensino e na pesquisa em administração?. Rev. adm. contemp., Curitiba, v. 18, n. 5, p. 695-709, Out. 2014. Disponível em: <http://www.scielo.br/scielo.php?script=sci_arttext\&pid=S141565552014000500695\&lng=en\&nrm=iso>. Acesso em: 26 Abr. 2016.

MENEGHETTI, F. K.; GUARIDO F. E. R.; AZEVEDO, A. Tréplica - A transcendência dos clássicos. Rev. adm. contemp., Curitiba, v. 18, n. 5, p. 736-744, Oct. 2014 . Disponível em: $<$ http://www.scielo.br/scielo.php?script=sci_arttext\&pid=S1415-

65552014000500736\&lng=en\&nrm=iso>. Acesso em: 27 Abr. 2016. http://dx.doi.org/10.1590/19827849rac201410674.

NICOLINI, A. Qual Será o Futuro das Fábricas de Administradores?. RAE-Revista de Administração de Empresas, v. 43, n. 2, abr-jun, 2003.

PARRY, M. Newly Discovered Draft of Marcuse Book Reveals Turn Toward Pessimism. Newfound EarlyDraft of Marcuse BookReveals a Turn Toward Pessimism - Research - The Chronicle of Higher Education. Set. 2013. pp. 1-4.

RASTOVIC, M. Marcuse's One-Dimensional Society in One-Dimensional Man. Agathos : An International Review of the Humanities and Social Sciences, 01 May 2013, Vol.IV(1), pp.111-125. Disponível em: <http://www.agathos-international-review.com/issue4_1/14.Articol\%20-

\%20Milos\%20Rastovic.pdf> Acesso em: 25 Mai. 2016

TEIXEIRA, J. C. ZANOTELI, E. J. CARRIERI, A. P. A Importância dos Clássicos na Formação do Pesquisador: o que nos diz os conceitos de socialização, identificação e campo intelectual como campo de poder. Revista de Ciências da Administração, Florianópolis, p. 154 - 171, abr. 2014. Disponível em: <https://periodicos.ufsc.br/index.php/adm/article/view/2175-8077.2014v16n38p154>. Acesso em: 01 fev. 2016.

WHITFIELD, S. J. Refusing Marcuse: Fifty Years after One-Dimensional Man. Dissent, Volume 61, Number 4, 2014, pp. 102-107. Project MUSE. Web. 24 May. 2016. Disponível em: <https://muse.jhu.edu/>. Acesso em: 24 Mai. 2016.

WOOD JR, T. DE PAULA, A. P. P. Pop-management: a literatura popular de gestão no Brasil. EAESP/FGV/NPP: Núcleo de Pesquisa e Publicações. Relatório de Pesquisa número 3, 2002. Disponível em:<http://bibliotecadigital.fgv.br/dspace/bitstream/handle/10438/2958/P00219_1.pdf?sequence=1\&isAll owed=y> Acesso em: 02 Fev. 2016.

WOLFF, R. P. What Good Is a Liberal Education? Qui Parle:Critical Humanities and Social Sciences, Vol.20(1), pp.137-151 2011. 